\title{
Клешнина В.Е. \\ Ограничение прав органов местного самоуправления при передаче отдельных государственных полномочий
}

Дальневосточный федеральный университет (Россия, Владивосток)

doi:10.18411/spc-20-03-2018-03

idsp: 000001:spc-20-03-2018-03

Конституция Российской Федерации предусматривает наделение отдельными государственными полномочиями органов местного самоуправления. Согласно ч. 2 ст. 132 Конституции Российской Федерации допускает наделение органов местного самоуправления отдельными государственными полномочиями, если такие полномочия переданы им на основе федерального закона или закона субъекта Российской Федерации, с передачей необходимых для их осуществления материальных и финансовых средств. Положения основного закона развиты и детализированы в отдельной главе 4 Федерального закона от 6 октября 2003 г. N 131-Ф3 «Об общих принципах организации местного самоуправления в Российской Федерации» (далее Федеральный закон № 131). В данной главе дается понятие отдельных государственных полномочий, определяется порядок наделения органов местного самоуправления указанными полномочиями, их осуществление и организация государственного контроля.

Согласно ч. 1 ст. 19 Федерального закона № 131 отдельными государственными полномочиями, передаваемыми для осуществления органам местного самоуправления, признаются полномочия органов местного самоуправления, установленные федеральными законами и законами субъектов Российской Федерации, по вопросам, не отнесенным настоящим Федеральным законом к вопросам местного значения.

Процесс наделения отдельными государственными полномочиями предполагает наличие взаимных прав и обязанностей для субъектов, участвующих в нем. Следовательно, можно выделить следующие группы:

- права и обязанности органов государственной власти и органов государственной власти субъектов Российской Федерации;

- права и обязанности органов местного самоуправления.

Основным и единственным правом органов государственной власти и органов государственной власти субъектов Российской Федерации является право наделения органов местного самоуправления отдельными государственными полномочиями Российской Федерации, субъектов Российской Федерации и отдельными государственными полномочиями по предметам совместного ведения Российской Федерации и субъектов Российской Федерации, если это не противоречит федеральным законам.

Часть 2 ст. 26.3 Федерального закона от 06.10.1999 № 184-Ф3 «Об общих принципах организации законодательных (представительных) и исполнительных органов государственной власти субъектов Российской Федерации» (далее Федеральный закон № 184) закрепляет 109 полномочий органов государственной власти субъекта Российской Федерации по предметам совместного ведения, из которых согласно ч. 6 данной статьи органы местного самоуправления не могут наделяться лишь 20 полномочиями.Следовательно, теоретически субъекты Российской Федерации могут наделить муниципалитеты отдельными государственными полномочиями в объеме, составляющем около 4/5 от общего числа их полномочий, поскольку количественных ограничений закон не предусматривает. 
Обязанностями органов государственной власти и органов государственной власти субъектов Российской Федерации, которые вытекают из положений ст. 19Федерального закона № 131, являются:

1) обязательное принятие федерального закона или закона субъекта Российской Федерации с определенным в частях 6 и 6.1 названной статьи содержанием передаваемых полномочий;

2) обязательная передача финансовых и материальных средств на их осуществление.

Также стоит отметить и скрытую обязанность, которую Бондарь Н.С. выявил путем анализа положений законодательства и позиции Конституционного суда Российской Федерации. Указанная обязанность предусматривает, что передаваемые полномочия должны быть связаны с решением вопросов местного значения и их наличие должно способствовать осуществлению основных функций местного самоуправления. Конституционный Суд Российской Федерации в определении от 15 января 2008 года № 219-О-О указывает: «наделение органов местного самоуправления теми или иными государственными полномочиями обусловлено необходимостью создания наиболее благоприятных условий для эффективной реализации соответствующих полномочий на конкретной территории и в конкретных социальноэкономических условиях». Из указанного следует, что передаваемые полномочия по своему характеру должны быть непосредственно связаны с жизнедеятельностью конкретного муниципального образования и интересами населения, учитывать потребности и возможности их реализации органами местного самоуправления. Тем самым, это будет способствовать эффективной реализации государственных полномочий, не нарушая саму природу местного самоуправления и не создавая трудностей органам местного самоуправления при их исполнении. Опираясь на идею Бондаря Н.С. важно отметить, что передаваемые полномочия могут быть связаны с решением вопросов местного значения, но не должным заменять либо дублировать существующие вопросы местного значения. Государственные полномочия должны находиться за рамками вопросов местного значения, поскольку недопустимо наделение органов местного самоуправления их же собственными полномочиями, как полномочиями государственными. К тому же ст. 19 Федерального закона № 131 прямо предусматривает, что отдельные государственные полномочия - это полномочия органов местного самоуправления по вопросам, не отнесенным к вопросам местного значения. По своей природе местное самоуправление является относительно самостоятельной формой народовластия, уровнем публичной власти, организационно и компетенционно обособленным от государственной власти. В качестве примера отдельных государственных полномочий можно привести полномочия по вопросам организации проведения на территории субъекта Российской Федерации мероприятий по предупреждению и ликвидации болезней животных, их лечению, отлову и содержанию безнадзорных животных, защите населения от болезней, общих для человека и животных. Указанные полномочия является полномочиями органов государственной власти субъекта Российской Федерации по предметам совместного ведения, установленным Конституцией Российской Федерации. На практике указанные полномочия часто передается органам местного самоуправления. Так, законом Приморского края от 29.02.2014 № 427-КЗ органы местного самоуправления городских округов и муниципальных районов Приморского края наделяются указанными отдельными государственными полномочиями Приморского края. В то время как ст. 15 и 16 Федерального закона № 131 данные вопросы не предусмотрены, то есть не являются вопросами местного значения. Однако передаются органам местного самоуправления с целью их эффективной реализации на территории конкретного муниципального образования. Другой пример, органы местного самоуправления муниципальных районов и городских округов Краснодарского края наделяются 
отдельными государственными полномочиями Краснодарского края по формированию и утверждению списков граждан Российской федерации, пострадавших в результате чрезвычайных ситуаций регионального и межмуниципального характера на территории Краснодарского края в соответствии с законом Краснодарского края от 10.04.2017 № 3597-КЗ. Указанные полномочия можно назвать косвенно связанными с вопросами местного значения, которые предусмотрены в ст. 15 (пункт 21) и 16 (пункт 28) Федерального закона № 131. Если кратко их сформулировать, то получаются вопрос организации и осуществление мероприятий по территориальной обороне и гражданской обороне, защите населения и территории муниципального района (городского округа) от чрезвычайных ситуаций природного и техногенного характера.

Таким образом, опираясь на приведенные примеры можно утверждать, что отдельные государственные полномочия не могут относиться к вопросам местного значения, однако могут иметь связь с ними, либо вовсе являться самостоятельными по отношению к вопросам местного значения.

Вторую группу составляют права и обязанности органов местного самоуправления, возникающие при передаче отдельных государственных полномочий.

Анализ статей 19 и 20 Федерального закона № 131 приводит к неоднозначному мнению по вопросу существования прав органов местного самоуправления в момент передачи. По сути, при наделении отдельными государственными полномочиями органы местного самоуправления не имеют никаких прав, так как они просто принимают определенные полномочия. В данном случае можно сказать, что это обязанность органов местного самоуправления.

В то же время на стадии осуществления отдельных государственных полномочий органы местного самоуправления имеют определенные в законе права. К их числу можно отнести следующие положения анализируемых статей 19 и 20 Федерального закона № 131:

1) право использовать собственные материальные ресурсы и финансовые средства для осуществления переданных им отдельных государственных полномочий;

2) право на осуществление отдельных государственных полномочий за счет субвенций переданных органам местного самоуправления;

3) право на осуществление отдельных государственных полномочий связанных с решением вопросов местного значения с точки зрения Бондаря Н.С. и приведенных ранее доводов. Указанное и вышеназванное права являются противоположными (корреспондирующими) обязанностям органов государственной власти Российской Федерации и органов государственной власти субъектов Российской Федерации.

4) право на отказ от осуществления переданных отдельных государственных полномочий в случае, предусмотренном в законе.

Обязанности органов местного самоуправления являются корреспондирующими правам органов государственной власти Российской Федерации и органов государственной власти субъектов Российской Федерации и выражаются в следующем:

1) обязательное принятие переданных отдельных государственных полномочий.

2) обязательное целевое использование переданных для исполнения отдельных государственных полномочий материальных и финансовых средств. Данная обязанность прямо не предусмотрена, однако, исходя из анализа ч. 3 ст. 20 и ч. 1 ст. 21 данного закона следует, что материальные и финансовые средства предоставляются на определенные цели. 
Таким образом, проанализировав существующие на сегодняшний день права и обязанности, можно констатировать тот факт, что право на осуществление отдельных государственных полномочий органами местного самоуправления превращается в обязанность. По сути, не существует возможности органам местного самоуправления решать вопрос о целесообразности принятия определенных государственных полномочий, способности их реализации на местном уровне. Отсутствие такой возможности порождает более серьезные проблемы: ограничение прав органов местного самоуправления на решение собственных вопросов, чрезмерную активность органов государственной власти субъектов РФ при передаче отдельных государственных полномочий. Все это может привести к утрате института местного самоуправления. Данной позиции придерживается и Васильева В.И., которая считает, что важно следить за тем и добиваться того, чтобы «государственные полномочия добровольно исполнялись не в ущерб решению вопросов местного значения, поскольку в противном случае может быть потерян социальный смысл существования и функционирования самого института местного самоуправления».

В связи с вышесказанным возникает вопрос, а не ограничиваются ли права органов местного самоуправления при наделении их отдельными государственными полномочиями? Для решения данного вопроса следует обратиться к законодательству.

В соответствии со ст. 133 Конституции Российской Федерации местное самоуправление в Российской Федерации гарантируется запретом на ограничение прав местного самоуправления, установленных Конституцией Российской Федерации и федеральными законами.

Вместе с тем в силу ч. 3 ст. 55 Конституции Российской Федерации права и свободы человека и гражданина могут быть ограничены федеральным законом в той мере, в какой это необходимо в целях защиты основ конституционного строя, нравственности, здоровья, прав и законных интересов других лиц, обеспечения обороны страны и безопасности государства. Данное положение корреспондирует с нормой ч. 3 ст. 3 Федеральный закон № 131 определяющей, что установленные Конституцией Российской Федерации и данным законом права граждан на осуществление местного самоуправления могут быть ограничены только федеральным законом в той мере, в какой это необходимо для защиты основ конституционного строя, нравственности, здоровья, прав и законных интересов других лиц, обеспечения обороны страны и безопасности государства.

При этом, как неоднократно указывал Конституционный Суд Российской Федерации, «публичные интересы, перечисленные в статье 55 Конституции Российской Федерации, могут оправдать правовые ограничения прав и свобод, только если такие ограничения отвечают требованиям справедливости, являются адекватными, пропорциональными, соразмерными и необходимыми для защиты конституционно значимых ценностей», в том числе прав и законных интересов других лиц и не затрагивают само существо конституционного права.

Таким образом, запрет на ограничение прав местного самоуправления не абсолютный, ограничение прав допустимо, но только при определенных условиях.

Рассматривая положения ст. 19 и 20 Федерального закона № 131 мы не встретим прямо предусмотренного ограничения прав органов местного самоуправления. Однако анализируя их можно выявить такие ограничения.

Во-первых, органы местного самоуправления имеют ограничение права на добровольное согласие принять передаваемые полномочия, на учет их мнения о целесообразности передачи и возможности органов местного самоуправления осуществлять данные полномочия не в ущерб собственным интересам.

Из смысла закона следует, что переданные государственные полномочия подлежать обязательному принятию органами местного самоуправления. Таким образом, возникает вопрос, а можно ли вообще считать осуществление отдельных 
государственных полномочий правом или это все-таки обязанность органов местного самоуправления? Если рассматривать практику передачи отдельных государственных полномочий, то можно найти значительное количество законов субъектов РФ о наделении муниципалитетов полномочиями. И это не удивительно, поскольку в Федеральном законе № 131 не предусмотрено количественных ограничений полномочий, подлежащих передаче. На практике отдельные государственные полномочия из «отдельных» превращаются в основные и преобладают в общем объеме полномочий органов муниципальной власти. Таким образом, можно сделать вывод о фактическом превалировании значимости государственных задач над вопросами местного значения в компетенции муниципалитетов.

Во-вторых, выявленное ограничение порождает более серьезные проблемы. Органы местного самоуправления затрачивают местный бюджет, поскольку субсидии, переданные на осуществление отдельных государственных полномочий, зачастую недостаточны для выполнения указанных полномочий.

Таким образом, средства, предназначенные для целей местного значения, начинают уходить на государственные. В результате права местного самоуправления, в частности право на решение задач местного значения за счет местного бюджета, ограничиваются.

Вышеназванные суждения подтверждает судебная практика.

Так, в апелляционном определении от 30.09.2017 № 33-2468 Костромского областного суда содержится мнение суда о том, что отсутствие передачи материальных средств для исполнения отдельных государственных полномочий не свидетельствует об отсутствии обязанности их исполнения. Верховный суд Республики Карелия в апелляционном определении от 26.05.2017 № 33-1822/2017 посчитал, что довод администрации муниципального района о недостаточности выделенной субвенции, позволяющей приобрести только шесть квартир для предоставления по договору специализированного найма, не являются основанием для предоставления отсрочки исполнения решения. В то же время Арбитражный суд Приморского края в решении от 06.06.2017 по делу А51-10425/2017 посчитал, что отсутствие финансирования в необходимом объеме ущемляет права муниципального образования.

Вывод, который следует из данного анализа, подтверждает довод о том, что ограничение прав местного самоуправления при наделении отдельными государственными полномочиями существуют.

Однако хотелось бы подробнее остановиться на праве органов местного самоуправления на отказ от исполнения отдельных государственных полномочий.

В соответствии с ч. 2 ст. 20 Федерального закона № 131 основанием для отказа от исполнения отдельных государственных полномочий является признанное в судебном порядке несоответствие федерального закона, закона субъекта Российской Федерации, иных правовых актов Российской Федерации, предусматривающих наделение органов местного самоуправления указанными полномочиями, требованиям, предусмотренным ст. 19 Федерального закона № 131.

На сегодняшний день такое несоответствие признается в процессе производства по административным делам об оспаривании нормативных правовых актов и регулируется главой 21 Кодекса административного судопроизводства Российской Федерации.

Таким образом, рассматриваемое право прямо предусмотрено в законодательстве Российской Федерации, принадлежит органам местного самоуправления и не может быть ограничено со стороны органов государственной власти.

Судебная практика в рамках рассматриваемого вопроса не совсем многообразна. Однако и в 2017 году проблема несоответствия акта, наделяющего органы местного самоуправления отдельными государственными полномочиями, остается актуальной. 
Так, Верховный Суд Российской Федерации в апелляционном определении от 22.11.2017 № 9-АПГ17-21 оставил в силе решения суда первой инстанции, признавшего недействующим пункты постановления Правительства Нижегородской области, которым органы местного самоуправления наделялись полномочиями в сфере обеспечения проведения капитального ремонта общего имущества в многоквартирных домах. Поскольку указанные полномочия являются государственными полномочиями и должны быть переданы посредством принятия закона субъекта Российской Федерации, а не путем принятия постановления высшим исполнительным органом государственной власти субъекта Российской Федерации, а кроме того, на осуществление указанных государственных полномочий не предусмотрены субвенции местным бюджетам. В указанном случае за защитой своих прав обратилась администрация муниципального образования, и ее требования были удовлетворены. Следовательно, орган местного самоуправления использовал свое право на отказ от исполнения отдельных государственных полномочий.

Еще одним апелляционным определение Верховного Суда Российской Федерации от 15.11.2017 № 30-АПГ17-3 оставлено в силе решение Верховного суда республики, которым признан недействительным закон субъекта Российской Федерации о наделении органов местного самоуправления отдельными государственными полномочиями по представлению земельных участков, государственная собственность на которые не разграничена. Судом установлено, что указанные полномочия не являются отдельными государственными полномочиями субъекта Российской Федерации и потому закон субъекта Российской Федерации издан с превышением полномочий, так как вопрос предоставления земельных участков уже урегулирован федеральным законом.

Приведенная судебная практика помогает поставить точку в вопросе и констатировать факт наличия полного и неограниченного права органов местного самоуправления на отказ от исполнения отдельных государственных полномочий.

Подводя итог, следует отметить, что анализ законодательства и судебной практики позволил разобраться в правах и обязанностях органов государственной власти Российской Федерации и органов государственной власти субъектов Российской Федерации, а также органов местного самоуправления; выявить ограничения указанных прав, а также обратить внимание на существующие проблемы.

$$
* * *
$$

1. Нормативно-правовые акты и другие официальные документы

2. Конституция Российской Федерации от 12.12.1993 // Собр. законодательства Рос. Федерации. 2014. № 31. Ст. 4398.

3. Бюджетный кодекс Российской Федерации от 31.07.1998 № 145-Ф3 // Собр. законодательства Рос. Федерации. 1998. № 31. Ст. 3823. (с посл. изм. и доп. от 28.12.2017).

4. Кодекс административного судопроизводства Российской Федерации от 08.03.2015 № 21-Ф3 // Собр. законодательства Рос. Федерации. 2015. № 10. Ст. 1391. (с посл. изм. и доп. от 28.12.2017).

5. Об общих принципах организации законодательных (представительных) и исполнительных органов государственной власти субъектов Российской Федерации: федер. закон от 06.10.1999 № 184-Ф3 // Собр. законодательства Рос. Федерации. 1999. № 42. Ст. 5005. (с посл. изм. и доп. от 29.12.2017).

6. Об общих принципах организации местного самоуправления в Российской Федерации: федер. закон от 06.10.2003 №131-Ф3 // Собр. законодательства Рос. Федерации. 2003. № 40. Ст. 3822. (с посл. изм. и доп. от 29.12.2017).

7. О наделении органов местного самоуправления отдельными государственными полномочиями Приморского края по организации проведения мероприятий по предупреждению и ликвидации болезней животных, их лечению, отлову и содержанию безнадзорных животных, защите населения от болезней, общих для человека и животных: закон Приморского края от 30.01.2017 № 472-К3. [Электронный ресурс]. - Режим доступа: www.consultant.ru.

8. О наделении органов местного самоуправления муниципальных районов и городских округов Краснодарского края отдельными государственными полномочиями Краснодарского края по формированию и утверждению списков граждан российской федерации, пострадавших в результате чрезвычайных ситуаций регионального и межмуниципального характера на территории 
Краснодарского края, и членов семей граждан Российской Федерации, погибших (умерших) в результате этих чрезвычайных ситуаций: закон Краснодарского края от 10.04.2017 № 3597-К3. [Электронный ресурс]. Режим доступа: http://www.kubzsk.ru/kodeksdb/noframe/law?d\&nd=462537514\&nh=5\&spack=110listid\%3D010000000 $100 \% 26$ listpos\%3D11\%26lsz\%3D3626\%26nd\%3D921000088\%26nh\%3D0\%26prevdoc\%3D921003960 \%26. - Загл. с экрана.

9. Аносов, Д.А. Проблемы определения порядка наделения органов местного самоуправления отдельными государственными полномочиями / Д.А. Аносов // Концепция развития института прав человека в условиях глобализации современного права и политики материалы ежегодн. научн.практич. конф. препод., сотрудн. и магистр.юридического факультета ВСГУГУ, 2016. Улан - Удэ: Восточно-Сибирский университет технологий и управления, 2016. С. 62-71.

10. Бабичев, И.В. Комментарий к федеральному закону «Об общих принципах организации местного самоуправления в Российской Федерации» / И.В. Бабичев, Е.С. Шугрина. 2-е изд., перераб. и доп. М.: Норма: ИНФРА-М, 2015. 269 с.

11. Васильева, В.И. О функциональном назначении местного самоуправления / В.И. Васильева // Журнал российского права. 2007. N 7. С. 13-23.

12. Гадельшина, Л.И. Содержание принципа передачи финансовых средств органам местного самоуправления, необходимых для осуществления отдельных государственных полномочий / Л.И. Гадельшина // Пробелы в российском законодательстве. 2014. № 1. С. 35-38.

13. Дитятковский, М.Ю. Обязательность передачи органам местного самоуправления материальных ресурсов и финансовых средств, необходимых для осуществления отдельных государственных полномочий / М.Ю. Дитятковский // Омский научный вестник. 2007. № 5 (59). С. 61-65.

14. Дитятковский, М.Ю. Порядок осуществления органами местного самоуправления отдельных государственных полномочий / М.Ю. Дитятковский // Современное право. 2007. № 2. С. 26-29.

15. Зайнутдинов, М.Н. Некоторые вопросы совершенствования реализации органами местного самоуправления отдельных государственных полномочий / М.Н. Зайнутдинов // Бизнес в законе. 2011. № 2. С. 11-13.

16. Иессен, Ю.А. Проблемы наделения органов местного самоуправления отдельными государственными полномочиями / Ю.А. Иессен, Н.С. Шашина // Модернизация российской экономики. Прогнозы и реальность: материалы II междунар. научн.-практич. конференции. СанктПетербург: Санкт-Петербургский академический университет. 2016. С. 153-159.

17. Казаков, В.В. Отдельные организационно-правовые вопросы финансового обеспечения в реализации органами местного самоуправления отдельных государственных полномочий / В.В. Казаков // Вестник Томского государственного университета. 2012. № 365. С. 101-107.

18. Муниципальное право Российской Федерации. В 2 ч.: учебник для бакалавров и магистров / под ред. Н.С. Бондаря. 5-е изд. М.: Издательство Юрайт, 2017. 356 с.

19. Об отказе в принятии к рассмотрению жалобы Главы городского округа Самара на нарушение конституционных прав на местное самоуправление абзацем третьим пункта 10 статьи 3 Федерального закона «О введении в действие Земельного кодекса Российской Федерации»: определение Конституционного суда РФ от 15 января 2008 года № 219-О-О. [Электронный ресурс]. - Режим доступа: www.consultant.ru.

20. По жалобе гражданина Филиппова Сергея Анатольевича на нарушение его конституционных прав статьями 106, 110 и 125 Уголовно-процессуального кодекса Российской Федерации: определение Конституционного Суда РФ от 18 июля 2017 г. № 1538-О. [Электронный ресурс]. - Режим доступа: http://www.garant.ru/products/ipo/prime/doc/71669120/\#ixzz55YGuNW5. - Загл. с экрана.

21. По апелляционной жалобе Правительства Нижегородской области на решение Нижегородского областного суда от 18 июля 2017 года: апелляционное определение Верховного суда РФ от 22.11.2017 № 9-АПГ17-21. [Электронный ресурс]. - Режим доступа: www.consultant.ru.

22. По апелляционной жалобе Народного Собрания (Парламента) Карачаево-Черкесской Республики на решение Верховного Суда Карачаево-Черкесской Республики от 28 июля 2017 года: апелляционное определение Верховного суда РФ от 15.11.2017 № 30-АПГ17-3. [Электронный pecypc]. - Режим доступа: www.consultant.ru.

23. По апелляционной жалобе главы Солигаличского муниципального района Костромской области на решение Чухломского районного суда Костромской области от 22 августа 2017 года: апелляционное определение Костромского областного суда от 30.09.2017 по делу № 33-2468. [Электронный ресурс]. - Режим доступа: www.consultant.ru.

24. По исковому заявлению Администрации Партизанского городского округа о взыскании с Российской Федерации за счет казны Российской Федерации 1601556 руб. для предоставления социальной выплаты: решение Арбитражного суда Приморского края от 06.06.2017 по делу А5110425/2017. [Электронный ресурс]. - Режим доступа: www.consultant.ru.

25. По частной жалобе администрации Пудожского муниципального района РК на определение Пудожского районного суда РК от 30 марта 2017 года об отказе в предоставлении отсрочки исполнения решения суда: апелляционное определение Верховного суда Республики Карелия от 26.05.2017 по делу № 33-1822/2017. [Электронный ресурс]. - Режим доступа: www.consultant.ru. 